\title{
Who Govern the World the Sovereign States or the World Bag?
}

\author{
Luigi Antonio Pezone* \\ Via Caserta, 33- 81055 Santa Maria Capua Vetere, Italy
}

Submission: August 21, 2018; Published: August 27, 2018

*Corresponding author: Luigi Antonio Pezone, Via Caserta, 33- 81055 Santa Maria Capua Vetere, Italy, Tel: +393405000280; Email: luigiantonio.pezone@gmail.com

\section{Opinion}

Open letter to the minister of labor and economic development of the Italian republic.Dear Minister of Labor and Economic Development of the Italian Republic Luigi Di Maio, Today, as you assert that "We are the state", I hope that in the short period in which you have occupied your important and strategic office, you have noticed that in your ministry is also included the Italian Patent Office. This office, in the opinion of the undersigned, is part of an international system, which goes beyond the interests of individual countries and the general interests of citizens but protects only the interests of large private property. However, the institution must be modified, not eliminated. Allow me to assert this, being the owner of forty deposits of Italian patents, five international and one European. I do not know if I will deposit the forty-first Italian patent because I am tired. If I do I will try to show that we can produce steel and incinerate solid urban waste without emitting dust, dioxins and $\mathrm{CO} 2$ into the environment, in spite of the consultants of the world governments and Italians who have been following the ILVA affair for years. We can already guess, briefly, how I would like to eliminate these serious environmental problems, which are not very different from the great thermal power stations that I have already faced in the indifference of the governments that preceded you in Italy and the world, and Italian entrepreneurs, that today the decree "Dignity" challenges you. Unfortunately, labor problems are not just normative and social. They are above all technical and scientific. The most enlightened world governments must find the courage to replace entrepreneurs to show that work is created above all by closing all the collateral cycles to industrial productions left open by entrepreneurs with the consent of the legislators and the silence of world science. In this regard, read the article of the undersigned http://www.spawhe.eu/development-and-the-environmentpenalized-by-science-and-international-laws/.

In this article I ask WIPO, the International Judges, and the UN, what I have already asked in other open letters: how can a private inventor, without money, submit to the rules that have imposed, not to see his own death work and their savings? The problem is very serious because the creative work is penalized. The only one who can create wealth and well-being towards the poorer classes. Technicians with inventive skills, who are employees, such as I have been for almost forty years, cannot do anything by being bound by business loyalty. They cannot even freely express their ideas if they are against the official line of the company they belong to. This dilemma, little known, which cannot be denounced by those directly involved, should be understood above all by politicians and legislators, but this does not happen in any country in the world. At the same time, I say: how can a person like myself, who has dealt with industrial and environmental facilities for a lifetime, do not try to correct the big mistakes he has noticed, at least as a retiree?

How did science not realize that the best general principle of energy is not that of thermodynamics, but the non-legislated law of fluid dynamics combined with gravity and compressed air pressure? Which worldwide scientific authority has granted patent offices the right to judge patents of public utility from a scientific point of view with generic statements such as "energy is not created from nothing"? Compressed air is not nothing and can be used in a much more rational way compared to the use made of it in the current autoclaves, by coupling these to the one-way circulation of the water fed with the pumps with the separate dual power supply, which they have the power to introduce into the pressurized recycle circuit the water expelled from the autoclave by the principle of impenetrability of the bodies, but after this has produced electricity in a current generator connected to a hydraulic turbine.

Science should respond personally, with the highest scientific authorities, to the very serious mistake committed. But this error affects our daily life, the air we breathe the water we drink, the energy we use to warm up and work to move, so it particularly affects the ministries of economic development and world labor. If we have failed the fundamental principles of energy and the way of working that does not produce wealth but debts and environmental disasters, we cannot continue to pretend anything. First, we must correct the errors and then program a new distribution of wealth. Otherwise where do we predict resources to make reforms? I dealt with this topic in particular in chapter 8 and 9 of the above article, which have the following titles, 
respectively: "The fluid dynamics combined with gravity and pressure is the real world energy force" - "The plants sustainable can be financed with the management savings obtainable from the scrapping of current plants In these two chapters, there is the essence of the economic development of the future that also allows us to respond to the oppositions, which provocatively ask where we take the money to make the reforms. If the opposition had heard, when they were in government, they too would have known how to design the industrial, environmental, energy, agricultural, urban rationally, and they would also know where they can get the money to make the reforms. But they did not listen. Unfortunately, economic development cannot be achieved unless one knows how to design, and one cannot design without first studying the scientific organization of global labor. This is demonstrated by the current public and private facilities that have warmed the planet. We are still year-zero in this direction, because even the new government, although animated by good will, could not have had any school or practical training, since the environmental and energy plants were wrong worldwide. The whole society is divided into scientific specializations and industrial productions in individual sectors that do not help to create sustainable global development. Even those who created the patent system did not make any distinction between patents of a commercial nature and patents of public utility, to which the patents concerning purification, desalination and energy systems belong. Therefore, it is difficult for a designer with transversal experiences, who proposes cross-sectoral patents to innovate the world's plants, to find private public interlocutors. The main reasons are two:

a) Above allworld public bodies should admit infrastructure design errors.

b) The exchange of existing patents between public researchers and private companies creates conflicts of interest.

These two problems are closely intertwined because they have not identified the best synergies between the general energy and purification principles, the adequate public infrastructures have not been created and dominated partial energy and purification solutions dominated by private companies that deal separately with water, air, energy with the specialist collaborations of public researchers. Unfortunately, the exchange of patents that has been created is one-way, from public to private. In fact, most governments have privatized the management of the environment, and energy, so the public researchers, in fact, carry out research and planning of support to private companies. In essence, public researchers take the salary from national governments, which also pay the fees for filing and maintaining patents internationally, but they work for multinational companies. The latter acquire only the patents that they like most and are not in contrast with the investments already made. Therefore with the purchase of patents do not finance public research, but the public inventors their allies. In fact, the proceeds from the sale of a public patent to a private company go for $50 \%$ to the inventors and $50 \%$ to the public body. What do governments gain from this trade? Nothing, on the contrary, they pay us back by research that does not create environmental benefits and does not create the work that could be created by demolishing and reconstructing obsolete plants that do not close the thermal, chemical, biological and nuclear cycles that open up. The current enslavement of public and private research creates work only if it suits the multinationals in the sign of the continuity of the systems that have polluted and heated the planet. The patent and legislative offices protecting industrial, not intellectual, property prevent the search for alternative energy and purification solutions.

To the rare inventors, such as myself, who are out of this circle of interests, and who identify new energy solutions, purification, desalination, which are public utility plants, the legislators demand the same taxes that apply for commercial patents. They do not understand that, unlike commercial patents, environmental patents must be disseminated. Industrial property must not be protected, but inventors must be protected, as the alliance created between public bodies and multinationals is penalizing the development, the environment and the fairness of the distribution of world wealth.

The world patent offices claim that the inventors claim the details of inventions to protect industrial property. But an inventor who already knows not to find public and private lenders because of the alliances created between public researchers and multinationals, claims the scientific principles identified, opposing the current system that sees independent inventors discriminated against other authors of works of intellect.

As I write this article comes the news from Legambiente, that the pollution just detected on the Italian coast is polluted or heavily polluted for $48 \%$ of the points sampled. Your government would lose my vote if it simply increased the number of purifiers equal to the current ones, which I installed for about twenty years, obeying the orders received You should learn from mistakes. Even if the number of existing purifiers is increasing, the problems cannot be solved because only a small percentage of the polluted water passes through the purifiers and with the current activated sludge treatment plants, in case of heavy rains, nothing goes through the purifiers. The solution is the production of interactive compressed hydropower in sewers, wells, basins, lakes, gulfs, ports, possibly combined with artificial rains in mini limestone greenhouses that as a side effect, in addition to solubilizing oxygen in the water to the effect of Henry's law also consume $\mathrm{CO} 2$ by producing purified and alkaline water at no cost, instead of the acid waters of the current purifiers, which as written in chapter 9 of the aforementioned article (http://www. spawhe.eu/development-and-the-environment-penalized-byscience-and-international-laws/) Public spending on sewerage and purification management is about 20 billion euros per year.

The ministries of world economic development if they really want to create sustainable development must equip themselves to immediately test the scientific principles identified by 
national inventors by selling them morally and commercially at international level with the same laws that publishers use to claim the originality of a work of art. literary or musical art. Who has established that the inventor of the centrifugal pump with the double separate power supply up to the impeller to which the international patent PCT / IT2016 / 000202 has been recognized must be forced to become a powerful international entrepreneur to receive recognition of his invention? International standards must be established to determine how pumps should be built to be more useful to society. Manufacturers must adapt. You can read the article http://www.spawhe.eu/pct-it2016-000202-openletter-to-w-i-p-o-and-the-international-legal-offices/, where I assert that this invention is very simple, but probably, it is also the most important of all time for energy and environmental protection, being the only invention that allows water to be recovered at no cost after it has produced the 'hydroelectric energy to reinsert it back into the volume of water producer of energy, in order to exploit for free the natural physical principles identified by Pascal, Torricelli and Henry long before the invention of electricity. The importance of this invention is made even greater by combining the compressed air of an autoclave tank, because it allows the use of one-way water in a hybrid circuit (open-closed), which due to pressurization and water recycling can take very small dimensions, to replace all current thermal engines of all sizes. From cars, to ships, to airplanes and to future spaceships. In fact, since the water is reinserted into the original volume of water instant by instant, neither the volume of water nor the volume of air nor the static pressure of the water producing energy in the turbine varies. Therefore, we can produce energy and water purification to infinity consuming only the wear of the machines, but without emitting even a gram of harmful gas into the atmosphere. Unfortunately, even public science, with its own silences, is demonstrating its own ignorance and disinterest in the practical application of the principles of energy conservation. While entrepreneurs are silent to defend investments made to produce existing pumps and plants. These problems are completely unknown to politicians and economists who want to rule the world. My current goal is to fight through my publications to raise awareness among the United Nations, the legislators, the governments, so that inventors of public utility patents pay no tax, in any country in the world, as patents like this and those connected, must be accessible to all countries in the world, such as medicines.

With my patents, which no one has financed, I wanted to show that at present, both governments and multinationals do very little for the protection of the environment. International justice and the United Nations, to which I wrote seventeen open letters without any response, do little. In all these letters, I invite the United Nations to separate intellectual property from industrial property, which, of course, as now, can also coincide if the inventor is an employee. I am asking for this change because with the current legislation private environmental inventors are highly penalized, not being able to face the costs of patent deposits and those of maintenance of the same pending unlikely public and private lenders interested in changing the current energy and purification solutions that have polluted and heated the planet.

Dear Minister Di Mayo, among all these great international organizations that think they are doing their duty, but only create bureaucratic obstacles, according to my experience, the most hostile to innovations is precisely the Italian patent office, which you today as Minister of Development economic Italian represent. This office, as I wrote in, http://www.spawhe.eu/developmentand-the-environment-penalized-by-science-and-internationallaws/, with a registered letter dated 22/05/2018, he invited me to transform the Italian patent application of pumps and turbines with separate double supply into a utility model application, according to articles 82-84DL. Vo n. 30/05. In essence, the Italian patent office, in contrast to the international office, says that this patent filing does not meet the requirements of the patent but of the utility model. If I had the money to complete the payment of international taxes, I would not be interested in the opinion of the Italian patent office, which did not understand the importance of the invention, if it wants to grant me the utility model instead of the patent. I try to explain the concept once again. Although the first centrifugal pump was invented around 1592 by an Italian citizen named Erne Alessandrino, and the first hydraulic turbines at the end of 1700 , the correct way to use them with maximum energy efficiency, is that indicated by the undersigned. But it is also necessary to modify the systems to be able to circumvent by means of the modified pumps, the gravitational force and the hydrostatic pressure on the delivery side. As explained in many publications and patents filed, not included, above all by the Italian patent office, we need two distinctly separate supplies up to the entrance in the impeller and only one outlet. This solution allows to add the two inlet flows as if it were a single flow and to exit with a single pressure by dynamically exploiting the principle of Pascal, which has shown that the greatest pressure expands in the entire passage section. Therefore, both the pumps and the hydraulic systems must be designed differently than the current state of the art to allow the recovery of the water after having produced energy by means of the turbines, as well as the energy saving in the lifting phase of the same waters, for means of recycling the water withdrawn on the delivery circuit. By balancing the inlet and outlet pressures of the impeller, it allows the entry of low pressure water on the suction side with lower energy expenditure, because the water must not be lifted but inserted in the recycling circuit equipped with greater pressure. This cannot be considered an option on how to build pumps and plants but a specific legislative obligation to which manufacturers of pumps and systems must comply, except in special cases, where the waters to be lifted contain too many bodies in suspensions which could damage the pump. But these innovations can only be achieved if we have competent people especially in public projects, which include these inventions and transfer their positive opinion to the legislators, who must issue the legislative decrees, to the pump manufacturers and in some cases even the turbines, so that adapt the building system to the best energy and water savings. 
As an inventor, I only fight for the recognition of intellectual property and copyright, which justice should recognize to all inventors of inventions of public utility, if these prove to be correct and will be implemented. Today there are no conditions for recognizing this elementary right, because the inconvenient environmental patents for the centers of power no one experiences them and nobody realizes them. Even if in some cases the patent is granted, without specific legislative decrees nobody can realize them. Therefore, even if the inventor had the money to pay the taxes that the legislators' regulations require in all the countries of the world, it would have been useless to pay them until the public bodies and legislators do not legislate the correct way to build the purification plants water, air, fossil energy cleaning, pumps, turbines, hydraulic lifting and water distribution systems. Until public bodies pretend that they do not understand these inventions, they do not realize them in their plants and do not impose them on private manufacturers, we cannot make big steps forward in protecting the environment and producing sustainable energy.

For the undersigned, social decrees on precarious work, pension reforms are not enough. An alternative development model is needed, where, above all, environmental and energy inventions are interactively linked together to close all the cycles that open up. If you close all the cycles, automatically, you also create more work (not parasitic but useful to society). These systems should have identified them as scientists working with the United Nations (IPCC Intergovernmental Panel on Climate Change). But these, even though they were awarded the Nobel Prize in 2007, have limited themselves to denouncing the seriousness of the problems and they are silent about the solutions not to be too many enemies in the centers of world power. We cannot expect much from world public science that does not design and obey the powerful rulers. Let us not forget that in recent years Italian public research on the order of a previous government was bringing French nuclear power into Italy and we only survived in danger for the nuclear disaster that took place on March 11, 2011 in Fukushima. We are attentive to the choices we make and seek sustainable development, because in Fukushima, more than seven years after the disaster, the situation is still very serious, with some areas showing values of radioactive contamination up to 100 times higher than normal values.

In the current international context, which has nothing to do with the ideologies of the class struggle of the last century and with the social problems that imply the Italian "dignity" decree, sustainable planning cannot be achieved unless we eliminate the conflicts of interest of public researchers who sell patents to multinational companies with the consent of the legislators. In addition, the patents they sell are individual machines or individual processes that do not belong to a global process and must be verified on a case-by-case basis if they are compatible with a global and interactive system, which at present no world institution has conceived. This vacuum of world power, created by art, to escape political, juridical, legislative and scientific responsibilities, among the many victims it has produced, also includes my national and international patent stores, which no center of power wanted to achieve many have been rejected by the Italian Patent Office, which today you represent, with formal observations, which have nothing to do with science and technology. As already written, the rules of patent lawyers are designed only to protect the industrial, not the intellectual, property of private inventors, who do not belong to public and private power centers, in one way or another, see their deposits of patents, granted or not granted, ignored by institutions and entrepreneurs.

The undersigned has lent himself to this perverse game of power, in which all the world's public research organizations, large private property, legislators, international judges and international politicians participate, to demonstrate that a model of industrial alternative development is possible, based on sustainable solutions studied in detail. This model, which they have not known or wanted to create is called SPAWHE (Synergic Plants Artificial Welling Hydroelectric Energy). In fact, sustainable development is made of synergies between different plants, the expansion of ocean exploration for environmental and food purposes and the correction of the fundamental principles of world energy, which are not thermodynamic but dynamic and electromagnetic fluids.

Dear Minister, if as politicians you change the laws and regulations on work and taxes to pay, because you believe that those who preceded you have made wrong laws, you must also have the courage to enter into the technical and scientific details that those who preceded you supported Even science is not infallible, especially the paid one that has warmed the planet. It can be said that the single established scientific principles are infallible. Even science is not infallible, especially the paid one that has warmed the planet. It can be said that the single established scientific principles are infallible. But when we talk about the design of the systems they rely primarily synergies between these principles that designers can put together to get the maximum performance with minimal expense and zero emissions. The best designers and inventors are not those that complicate the plants, but those that manage to identify low-cost strategic inventions that avoid opening cycles that cannot be closed perfectly, such as thermal and nuclear ones.

The current development model leaves too many open cycles that have warmed the planet and created environmental and nuclear disasters. We must deduce that, despite the large amount of scientists who have worked there and the large capital invested, public and private, is a model of improvised development, not coordinated by the authorities, not properly sized and not developed in all the details, otherwise we would not have the current environmental problems.

The website http://www.spawhe.eu was born in September 2014 when, after eight years of work, I identified the general principles of purification and energy production compatible with the terrestrial environment, but I had not yet identified the 
pressurized hydroelectric energy that allows higher yields. For this reason, this is the only website that has two "home pages". The old one and the new one. Who wants to understand everything from the origins of my reflections on the organization of work, environment and energy must start from the old "home page" and climb up to the new one, starting with the inventions that took place in 2015 to 2018, which do not upset the previous ones, only increase returns because the general principles are respected. Instead, they upset the current energy and purification plants, highlighting the defects that led to global warming, the increase in floods, desertification, the inability to dominate the major world fires. The SPAWHE system does not violate the scientific principles legislated by the fathers of science but applies them synergistically by studying the global organization of scientific work considering all inventions that were not financed before 2015 to be integrated, integrating them with the subsequent ones that with the introduction of compressed air into the systems already identified multiplies the energy and purification yields. While world science is silent and hiding, the Italian patent office states that energy does not come from nothing, despite all the technical documentation presented. Among other things, also published on the Internet because the undersigned does not fight for industrial property. I would appreciate the official answers related by those who govern the Italian scientific world. I am not interested in legal actions against patents that are not granted, because even the patents that have been granted to me no one has ever made them. The current concept of a patent, which does not recognize intellectual property separate from the industrial world-wide context. The inventors do not necessarily have to be tied to the entrepreneurs and to the centers of world power, and the patent deposits do not have to lapse if nobody finances them and nobody realizes them. Obviously, dormant patent deposits, which do not create any profit, do not have to pay taxes of any kind.

The SPAWHE development model has the merit of not even costing a dollar or euro to the world institutions, as it is based only on logical reasoning of those who have worked for half the life in industrial plant design and half in the environmental one, seizing the advantages and defects of both sectors. This model demonstrates that research can also be done without great economic resources, simply assuming that the pumps, hydraulic systems, turbines, fans and connections between systems that do not exist today are operating differently. If from this model of virtual development, it turns out that we can produce hydroelectric energy by recycling pressurized water on itself in partially open circuits, what is the use of investing in large reservoirs and large dams? If with the same system we can produce all the energy needed on board transport, including air transport, before constructing kilometers of tunnels and viaducts to cross the mountains, it is no longer prudent to experiment, these strategic inventions that create colossal structural works that cost billions and disfigure and damage the environment. If by exploiting the synergies between compressed air and incompressible water we can produce all the energy we need with small encumbrances, what is the use of all the works to extract, transport and refine gas and oil? What are the cumbersome wind turbines and the even more cumbersome solar panels, with discontinuous production and low yields?

Dear Minister Di Maio in these twelve years that I have proposed environmental and energy inventions, all those who have preceded you in Italy and in the world, have not responded to obvious interests of part, because these proposals are not from a novice who works of fantasy, but by a pensioner who takes responsibility for what he writes. Sustainable development is possible only if the intertwining of interests between public and private is cut and a disinterested collaboration is established. The patents of social utility produced by researchers and inventors who are not entrepreneurs should not be sold to individuals, but made available to everyone, recognizing intellectual property and copyrights to inventors. The industrial property of patents must be recognized to industrials only on the patents that companies produce on their own. The current patent system that rewards only industrial property is destroying the search for sustainable solutions to favor those that produce immediate profit without deepening all the negative side effects involved in the trade of solutions not integrated into the environment due to technical and scientific shortcomings industrial products, or because of the lack of infrastructure that the state should achieve. Just think of the fixed and mobile heating systems, those of heating, air conditioning, desalination, chimneys, sewers and purifiers located tens of kilometers from sources of pollution, but also to high ovens and incinerators. They are all incomplete works and not integrated into the environment.

The industrial system and the health system reason in the same way. I extract from Anita Botwin's article https:// www.conoscenzealconfine.it/la-nostra-cattiva-salute-e-moltosalutare-per-l-industria-farmaceutica/ the following sentence concerning the health system: "L The current research model does not invest in knowing more about diseases that are not profitable and imposes exorbitant prices on new medicines, playing with the lives of patients and endangering the sustainability of health systems ". The same thing happened in industrial, environmental and energy systems. Since the advent of the industrial age, no one has been investigating unprofitable solutions for entrepreneurs, who have to sell oil products and technologies that are quite complicated to scare off interlocutors who want to protect the environment, especially trade unions and environmentalists. These, not knowing how to design the plants independently, consider a victory the use of methane instead of coal in thermal power stations, or instead of diesel fuel on transport vehicles. This is due to the fact that world public science has not corrected the mistakes made by private industry, but has supported it by selling unnecessary patents and preventing the sustainable solutions proposed by private developers without soda be tested in public laboratories. The Patent Offices did the rest, forcing the moneyfree inventors to claim industrial property and demanding that 
the public utility patents pay the deposit and maintenance fees like the commercial ones. In addition, in some cases, patent offices claim the right to judge patent deposits also from a scientific point of view, stating that hydropower with water recycling can not be produced as contrary to the principles of conservation energy. The same is true of submerged hydropower, sustainable desalination with ion exchange in floating spheres and compressed hydropower, which for me is the true energy of the future.

Dear Minister Di Maio, I do not know who has granted the proxy to the Italian patent office to replace world science. I do not even know if there is any world authority that can grant such a proxy to someone. I only know that science is divided into many sectors and does not respond because it cannot answer things that it has not experienced and probably cannot even experiment to not discover the Pandora's box. I also say that the patents offices on patents of public utility should simply register patent deposits without making judgments, if they do not want to involve also the public institutions they represent. The undersigned, not in a hurry. He simply stated how to construct air and energy purification plants to be sustainable and interact positively with the environment. If the law is the same for all authors of works of intellect, when the truth is established, international justice should recognize the copyright. It did not make sense to realize in Italy in 2015 the electronic filing of patents that costs only 50 euros, and then force the inventors to spend 600 euros to make legal claims against the arrogance of patent offices that allow you to scientifically judge inventions that do not they understand precisely because they are novelties that have escaped even to science, which has been divided into sectors and has never worked synergistically to identify these inventions. There is no point in combating legal recourse, which would only make sense if the inventors had the chance to become entrepreneurs worldwide. I do not fight for industrial property because my patent stores are of public utility. As such, they must be disseminated unprotected, hoping that international justice will recognize the copyright. As it is clear that a swallow does not make spring, no invention can change the world development, if the inventions are put together randomly on the territory, as it currently happens. SPAWHE is not a model of impromptu development because the forty deposited patents are linked to each other making a progression of the global state of the art. It is not important whether the patents have been understood or not understood by the world's ruling class. It is also not important to investigate the reasons why these patents were not included. It is important and that they have been deposited. History will judge the value of scientists and one-way entrepreneurs who have warmed the planet for not understanding how the plants should be designed and connected to the territory. But history will also judge the politicians and legislators who let them do it without experiencing the uncomfortable solutions of those who assert that the entire industrial development has been wrong since before we were born the wrong principle of energy. The world has warmed up by having chosen thermodynamics instead of dynamic fluid. The world has warmed up by having chosen thermodynamics instead of dynamic fluid. Is not it strange that in recent years the global anthropogenic $\mathrm{CO}_{2}$ emissions have decreased, but at the same time the percentage of $\mathrm{CO}_{2}$ in the environment has grown more than in the past? The reason for this strange phenomenon the ministries of world economic development should know it more than other ministries, because the planet is acidifying, especially the waters. Acidification is a phenomenon that releases to the atmosphere the $\mathrm{CO}_{2}$ that cannot be retained by bicarbonates present in fresh and salt water, in particular those of calcium and magnesium. Therefore with the increase of oceanic temperature the bicarbonates precipitate turning into carbonates, the $\mathrm{CO}_{2}$ rises towards the atmosphere and the level of the ocean waters increases also for the melting of the glaciers $\left[\mathrm{Ca}\left(\mathrm{HCO}_{3}\right)_{2} \rightleftharpoons \mathrm{CaCO}_{3}+\mathrm{CO}_{2}+\mathrm{H}_{2} \mathrm{O}, \mathrm{Mg}\left(\mathrm{HCO}_{3}\right)_{2} \rightleftharpoons \mathrm{MgCO}_{3}+\right.$ $\left.\mathrm{CO}_{2}(\mathrm{~g})+\mathrm{H}_{2} \mathrm{O}\right]$. Decarbonizing the planet does not mean replacing the cars with the thermal engine with the battery but changing the primary energy source. Even if we were able to build batteries so powerful that they could also be used on agricultural crops and large means of transport, the primary energy source would still be the same. The world's ruling class is making itself ridiculous in the face of future generations because it has neglected the only sustainable energy that can be produced on planet Earth, while it has developed all the other more polluting and low yields.

The latest finding of American President Trump is that of conquering space with weapons to support American dominance even in space. For myself, we should instead conquer space to prevent destructive astrophysical phenomena and nuclear wars, creating artificial satellites that reproduce the habitat of human life, autonomously energetically capable of producing all the energy needed for human nutrition and the construction of spare parts and be ready for partial or total evacuation of the planet in case of need. We can do this only if we produce on board transport vehicles and energy satellites with water and air in the various forms described on http://www.spawhe.eu/the-lost-civilizationseinstein-s-thought-and-survival-energy/. But on this we are at zero because none of the one hundred and ninety-six sovereign states have spent a single euro, including Italy, in this direction. Until now, world governments have preferred to buy energy from multinationals so as not to force the meninges of public researchers working at the service of the multinationals themselves to help them reduce emissions but paid by taxpayers. Energy without fuel and without polluting emissions has been neglected, which has nothing to do with perpetual motion, respecting the principles of Pascal, Torricelli, Henry, and inventions on the electromagnetism of Ferrari and Tesla, wearing only the materials of the pumps, turbines, compressors, valves used to make the circuits. No heat is needed because energy has always produced the pressure for the flow rate due to the density of the passage fluid, which is not air but water, which has a density 830 times higher than air. Since the advent of the industrial age, science has not been able to develop pressure without the heat produced by fuels, nuclear energy or paid hydrogen extracted from methane or water hydrolysis. 
Dear Minister Di Maio this is the world that you have inherited from those who preceded you. I hope that before spending the scarce resources that you want to make sure with confidence if at least those who preceded, has guessed the fundamental principles of energy. I am sure that the choices made on the fundamental principles were also wrong, and I believe I have amply demonstrated it without economic means. Only those who have studied the principles of energy by heart cannot understand. With this I do not invite Italy to leave Europe to avoid the end of Turkey. I invite the Italian government to work in favor of creativity in world public projects to change Europe and the whole world.

I'm sorry to say it, but I do not believe in politics and the economy. I believe the world must be governed scientifically. But science must be applied by advancing the state of the art globally. This means that it is counterproductive to follow obsolete cleaning and energy systems, competing with each other, only because no one has studied the maximum potentials obtainable through the organization of work, which would inevitably lead to the individuation of interactive energies. Yet entrepreneurs are well aware that only by organizing the work capillarity and applying the best automation technologies, in the industrial plants can be produced thousands of cars or refrigerators or televisions in a single day. Why does the organization of work not apply to the entire global economic development to increase the potential for environmental protection and sustainable energy production by choosing the best automation technologies? In environmental and energy systems, automating means exploiting more than one scientific principle legislated with the help of existing technologies. The Spawhe system has studied the organization of work in this direction, coming to the conclusion that we do not need battery-powered cars, or hydrogen that becomes a fuel, or divide the atom to develop new energy. There are enough only the technologies already developed, to replace the thermal energy with that compressed hydroelectric to multiply the energy yields and purification, creating a model of sustainable development for all. But this system can still improve returns with research on electromagnetism, starting from an energy source that costs nothing and even protects the environment. It's all written in black and white at http://www.spawhe.eu, but global governments and multinationals continue to shut up and select the best brains to put public and private science at the service of global stock exchanges. It should be the opposite. The global scholarships should be adapted to the scientific choices made by studying globally and impartially the solutions in the interest of all by the best brains selected by the ministries of economic development and by the United Nations.

The good solutions studied by the multinationals can also be appreciated, but the state of the art must above all determine the world public bodies, imparting impartially, from all sources, the ability to design and selecting the best solutions. This does not happen today because professional statesmen and entrepreneurs who have turned into statesmen to defend their investments and their power, prevent proper economic development, which should be the result of rigorously scientific choices and a widespread organization of work. world. The tragic event of the collapse of the viaduct in Genoa that happened while I was about to publish this article led me to delay the publication that might seem out of place and not respectful of the victims of the tragedy. But I decided to publish it anyway, adding some other considerations. Even this disaster shows that we are not governed by governments but by the powerful of the earth, which in addition to making us pay taxes on income, on products, also make us pay tolls on the roads and require us to buy fuels that pollute their production because we they are mastered as well as sources of supply, including world science, public and private, which does not dare to invent unsupervised energy and purification systems.

Dear Minister, if I am right, with the energy that will not cost almost nothing, as I have already written, it will not agree to build tunnels and viaducts, the great distances will be traveled flying in the atmosphere without polluting it, with less infrastructure, without consuming tires. But only the wear and tear of rotating machines, more and more efficient and light thanks to the progress we make in the search for materials and electromagnetic efficiency. Unfortunately, in the world, in addition to the companies that manage the motorways, thinking only of profit, there are many hens that produce golden eggs for those already rich and all carry out work with incomplete technologies or scientific principles. Just think of the multinationals of large hydroelectric works, those of transport, air conditioning, purification of water and air strictly separate; of steel, incinerators, biomass, and biotechnology, solar and wind energy. All world science is divided into separate sectors, carefully avoiding interactivity between processes, which could create the leap in quality and show the limits of current solutions.

Of course, I have already understood that even you young people do not believe me, but I remind you that you have come to power, thanks to one of my peers, as capable as myself, yet to dream and to reason with his own head. Your government would still be a dream if Beppe Grillo had not been able to dream keeping his eyes wide open. Until proven otherwise is the need that sharpens the wits. If I had been a super-paid manager or inventor, I would never have been able to think of my sustainable solutions, which are the ones that only look for those who have nothing to spend on research, but make better use of what surrounds us. I have collected the silences that I collected in Italy, even abroad. Not because the solutions are wrong, but because none of the few who understand them can speak freely, without violating the loyalty of the company, imposed by employers, public and private. It is no coincidence that the website http: // www.spawhe.eu, in the "new home page" has registered, up to now about 21,000 visitors. All strictly silent and waiting for the events. It is right that this is so, as long as those who go to parliament in each country also take into account that there are many people who cannot openly express their technical and scientific opinion without risking their jobs. These people are those who best know how to effectively solve 
the problems of development and work. Among these people there was also the undersigned, who preferred to retire to be the inventor free from conditioning without being paid by anyone.

If I were a statesman I would mainly reform world public planning, eliminating the current patent trade, and claiming, as I have extensively written about SPAWHE, that all the cycles involved in public and private processes are closed in the planned plants or in those adjacent, already existing, or designed at the same time. You do not need anything else to create work and sustainable development. But this concept had to be understood at the beginning of the industrial era. Today it involves the substantial modification of all the world's plants, public and private, fixed and mobile, having wrong the fundamental principles of world energy. It is a universal fortune that the studies carried out by myself have led to the identification of interactive energy that is much more powerful and efficient than fossil energy and current renewable energy. Unfortunately, it is also the habit that the monk does. If I had not been left alone by the national scientific institutions to talk about interactive energy, today the ITALIA system and the SPAWHE system would have many common points to start again with a new model of development, which has nothing to do with what the multinationals, unfortunately supported by public researchers and world legislators. It is clear that I believe the start of the procedure for revoking the concession to the company that manages the Italian motorways is a positive sign of change and I hope that they will also follow other revocations. But the assignment of management to the current Italian ruling classes, public and private, is not even a guarantee because of corruption and hidden conflicts. For this reason we need a scientifically organized and tested model of development, where nothing can be improvised during procurement and management. Everything must be precisely defined at the design stage. This is not impossible using the interactive energy and purification systems that open a few cycles but with fixed and mobile self-depurative systems that avoid large structural works, deteriorating from time, from seismic and geological phenomena. But as I explained in this article and many others, on this road we are at zero and I do not think you are ready to follow it. I only hope that before making investments with the scarce Italian resources, you will find at least the courage to do the scientific checks that are very cheap and that of those who preceded you to the government of Italy, Europe and the World have done, being all involved up to the neck with the current development model. From the choices you will make not only to better distribute wealth, but also to create it, the future of Italians will depend. If everything works, as it should, the Italian positive experience could represent an example of transparent sustainable political, scientific and technological growth for all the other 195 Sovereign States.

This work is licensed under Creative Commons Attribution 4.0 License

DOI: 10.19080/IJESNR.2018.14.555879

\section{Your next submission with Juniper Publishers} will reach you the below assets

- Quality Editorial service

- Swift Peer Review

- Reprints availability

- E-prints Service

- Manuscript Podcast for convenient understanding

- Global attainment for your research

- Manuscript accessibility in different formats

( Pdf, E-pub, Full Text, Audio)

- Unceasing customer service

Track the below URL for one-step submission https://juniperpublishers.com/online-submission.php 